Gynecologic and

Obstetric Investigation
Gynecol Obstet Invest 2012;74:313-319

DOI: $\underline{10.1159 / 000338996}$
Received: February 1, 2011

Accepted after revision: April 27, 2012

Published online: October 11, 2012

\title{
Uterine Endometrial Carcinoma: 10 Years' Experience with Long-Term Follow-Up at a Single Korean Institution
}

\author{
Eun-Ju Lee ${ }^{a}$ Tae-Joong Kim ${ }^{b}$ Chel Hun Choi ${ }^{b}$ Jeong-Won Lee ${ }^{b}$ Je-Ho Lee ${ }^{b}$ \\ Duk-Soo Bae ${ }^{b}$ Hyoung Moo Park ${ }^{a}$ Byoung-Gie Kim ${ }^{b}$
}

Departments of Obstetrics and Gynecology, at a Chung-Ang University School of Medicine and

bSamsung Medical Center, Sungkyunkwan University School of Medicine, Seoul, Korea

\section{Key Words}

Endometrial cancer $\cdot$ Korean $\cdot$ Prognostic factor

\begin{abstract}
Aim: To evaluate prognostic factors in Korean patients with endometrial cancer. Methods: A retrospective analysis was conducted on 248 patients who were staged surgically at the Samsung Medical Center between 1995 and 2004. Survival data were analyzed using Kaplan-Meier estimates, and multivariate analysis was performed using the Cox regression method. Results: The median age was 51 years (range 2175), which was younger than in previous studies in Western patients, and the age of 50 years was the cutoff to predict survival. More than half (55.6\%) were normal weight or underweight $(\mathrm{BMI}<25)$. Multivariate analysis revealed that age, Fédération Internationale de Gynécologie et d'Obstétrique (FIGO) stage, and histopathology were independent predictors of disease-free survival, and FIGO stage and p53 mutation were independent prognostic factors for disease-specific survival (DSS). The 5-year DSS for patients with stage I, II, III and IV disease was 95.6, 93.8, 69.8 and 50\%, respectively. The 5-year DSS rate for patients with a p53 mutation was $84.4 \%$, compared with $97.1 \%$ for patients without. Conclusions: Korean patients with endometrial cancer were young-
\end{abstract}

er and had a lower BMI than previously reported. Furthermore, age greater than 50 years was predictive of a poor outcome. Age, FIGO stage, histopathology and a p53 mutation were independent prognostic factors for survival.

Copyright $\odot 2012$ S. Karger AG, Basel

\section{Introduction}

Endometrial carcinoma is the seventh most common cancer in women worldwide [1]. Between 1987 and 2006, the number of women in the United States who were newly diagnosed annually with endometrial cancer increased from 35,000 to 41,200 [2]. In contrast to this gradual increase in the USA, the incidence of endometrial cancer has increased dramatically in Asia. The total number of cases in Japan was 976 in 1983, 2,115 in 1994 and 4,267 in 2005 [3]. In Korea, the registered number of endometrial cancer cases was 132 in 1991, 239 in 1994, 425 in 2000 and 862 in 2004 [4]. The increased incidence of endometrial cancer in the USA reflects in part the increase in obesity, a growing problem worldwide, and aging of the popula-

\section{E.-J.L. and T.-J.K. contributed equally to this study.}

\section{KARGER}

Fax +4161306 1234

E-Mail karger@karger.ch

www.karger.com (c) 2012 S. Karger AG, Basel

$0378-7346 / 12 / 0744-0313 \$ 38.00 / 0$

Accessible online at:

www.karger.com/goi
Byoung-Gie Kim

Department of Obstetrics and Gynecology, Samsung Medical Center

Sungkyunkwan University School of Medicine, 50 Irwon-dong, Gangnam-gu Seoul 135-710 (Korea)

Tel. +82 23410 3513, E-Mail bgkim@ @kku.edu 
tion, but no information is available on the increase in Asian women. There is little doubt that endometrial cancer will continue to be of major concern for all health care professionals.

Various clinical and pathological prognostic factors for endometrial cancer have been reported. Patient age, histopathology type, Fédération Internationale de Gynécologie et d'Obstétrique (FIGO) stage, tumor grade, myometrial invasion, steroid hormone receptor status, DNA index and p53 mutation status have been correlated with patient survival [5-10]. However, previous studies included inconsistencies with regard to the significance of these various factors. In the present study, the clinical and pathological features associated with endometrial cancer were evaluated in a large series of Korean patients from a single institution with long-term follow-up. Additionally, independent factors associated with the prognosis of endometrial carcinoma in Korean women were determined using a multivariate analysis.

\section{Materials and Methods}

\section{Patients}

In total, 248 patients with histopathologically proven endometrial carcinoma were included. Patients with uterine sarcomas, malignant mixed Müllerian tumors of the uterus, or a secondary malignancy were excluded. Patients who died from unrelated diseases were not included. Patients enrolled in this study underwent staging surgery as primary treatment between 1995 and 2004 at the Department of Gynecological Oncology, Samsung Medical Center, Seoul, Korea. Surgical staging procedures were defined as a total hysterectomy, bilateral salpingo-oophorectomy, pelvic cytological evaluation and pelvic lymphadenectomy. Twenty-three (9.2\%) of the patients underwent laparoscopy. Forty-two (16.9\%) of the patients had incomplete staging (without oophorectomy and/or pelvic lymph node dissection) for grade 1 disease, and were diagnosed as having superficial invasion on frozen sections taken from young women. Eight patients had a para-aortic lymphadenectomy with pelvic lymphadenectomy and these nodes were negative on histopathology.

A database was generated based on information from the hospital records, including surgical notes and pathological reports. Information collected included: age, weight and height of the patients; additional systemic diseases, such as diabetes mellitus, hypertension and malignancy; type of surgery; tumor stage; histopathological tumor type; tumor grade and recurrence. Body mass index (BMI) was calculated as weight/height squared in kilograms/square meter. None of the patients had received preoperative pelvic radiation. Disease stage was assigned based on surgical and pathological findings according to the FIGO staging system [11]. Experienced pathologists reviewed all histological specimens. All tumors were classified according to the WHO/ISGPY classification [12]. Mixed carcinoma was defined as a combination of two or more pure types, in which the component account- ed for at least $10 \%$ of the tumor. The tumor grade was evaluated for both architectural and nuclear grades [13]. The depth of myometrial invasion was described as none, inner half, or outer half.

\section{Statistical Analysis}

The primary outcomes evaluated were disease-free survival (DFS) and disease-specific survival (DSS). DFS was defined as the time in months from the time of the last therapy to any recurrence. DSS was defined as the time from surgery to the time of a known cancer-related death. DFS and DSS were evaluated using Kaplan-Meier estimates and compared using the log-rank test. Median values were analyzed using the nonparametric MannWhitney $U$ test. Dichotomous groupings were analyzed using the $\chi^{2}$ and Fisher's exact tests, as appropriate. Multivariate analysis was performed using the Cox regression method. All $p$ values were two-sided, and statistical significance was defined as $\mathrm{p}<$ 0.05. Statistical analysis was performed using SPSS version 15.0 (SPSS Inc., Chicago, Ill., USA).

\section{Results}

The study population consisted of 248 patients diagnosed with primary endometrial adenocarcinoma. Their demographic characteristics are presented in tables 1 and 2 . The median age of the patients was 51 years (range 21-75). In total, 105 (42.3\%) patients were less than 50 years old. According to the World Health Organization's definitions, 138 (55.6\%) were normal weight or underweight (BMI <25); 82 (33.1\%) were overweight $(25 \leq \mathrm{BMI}$ $<30)$ and $28(11.3 \%)$ were obese $(\mathrm{BMI} \geq 30)$. One hundred thirty-three $(53.6 \%)$ patients were premenopausal. The most common presenting symptom for patients with any disease stage was abnormal spotting/bleeding (75.8\%). Nine patients (3.6\%) had a history of malignancy and $44(17.7 \%)$ had a history of diabetes or hypertension. Thirty-six (14.5\%) patients had a family history of malignancy. Patients with a family history of gynecologic cancers included 4 uterine endometrial cancers and 1 cervical cancer.

Table 3 summarizes the histopathology of the tumor types. The most common type was endometrioid adenocarcinoma. Pure endometrioid type and mixed carcinoma with a dominant endometrioid component accounted for 85.9 and $4.8 \%$ of cases, respectively. Two mixed serous and endometrioid carcinomas included 10 and $15 \%$ serous components, respectively. These were classified as endometrioid type in the survival analysis because mixed carcinomas containing $25 \%$ or greater serous component behave as pure serous carcinomas [14]. Each mixed clearcell and endometrioid carcinoma contained a $10 \%$ clearcell component. Twenty-three cases (9.3\%) were classified as nonendometrioid tumor types. 
Table 1. Demographic characteristics of the 248 patients with endometrial cancer

\begin{tabular}{lc}
\hline Characteristics & \\
\hline Median age (range), years & $51(21-75)$ \\
Median BMI (range) & $24.6(16.6-38.3)$ \\
Menopause & $133(53.6)$ \\
$\quad$ Premenopausal & $113(45.6)$ \\
Postmenopausal & $2(0.8)$ \\
Unknown & $188(75.8)$ \\
Presenting symptoms & $24(9.7)$ \\
Abnormal spotting/bleeding & $16(6.5)$ \\
Incidental (routine checking) & $9(3.6)$ \\
Menorrhagia & 4 \\
Abdominal symptoms & 3 \\
Postoperative (myoma) & 4 \\
Palpable mass & $9(3.6)$ \\
Others & $44(17.7)$ \\
Personal history of malignancy & 10 \\
Diabetes mellitus/hypertension & 24 \\
Diabetes mellitus only & 10 \\
Hypertension only & $36(14.5)$ \\
Diabetes mellitus and hypertension & $41(16.5)$ \\
Family history of malignancy & \\
Nulliparous & \\
\hline
\end{tabular}

Unless otherwise specified, the data represent numbers and percentages (shown in parentheses) of patients.

Table 2 summarizes the clinical/pathological characteristics of the cases. The majority of cases were grade I tumors (69.4\%) and were diagnosed as FIGO stage I (79.8\%). Approximately $24 \%$ of the total study population $(60 / 248)$ had deep myometrial invasion $(\geq 1 / 2)$. Sixteen patients $(6.4 \%)$ had pelvic lymph node involvement and 40 (16.1\%) had abnormal serum CA125 levels. The status of p53 mutation, estrogen receptor (ER) status and progesterone receptor (PR) status were positive in 27 (10.9\%), $100(40.3 \%)$ and $102(41.1 \%)$ patients, respectively.

Because the median age of the patients was 51 years, which is much younger than that in prior studies, the patients were stratified by age ( $47-65$ years), and survival was compared between women below and above the threshold age. A univariate analysis revealed that DSS was always significantly better in younger patients. However, this was not the case in the multivariate analysis (fig. 1a). When the patients were stratified by age, DFS was significantly better in the 47-55-year-old group, but not in the 56-65-year-old group. Moreover, when the women were stratified as 49,50 and 51 years old, DFS was significantly different in multivariate analysis adjusted

Uterine Endometrial Cancer: 10 Years' Experience
Table 2. Patient characteristics and univariate and multivariate analysis of 5-year DFS and DSS rates

\begin{tabular}{|c|c|c|c|c|c|}
\hline & \multirow{2}{*}{$\begin{array}{l}\text { Patients } \\
\mathrm{n}\end{array}$} & \multicolumn{2}{|c|}{ Univariate $\mathrm{p}$ value } & \multicolumn{2}{|c|}{ Multivariate $\mathrm{p}$ value } \\
\hline & & DFS & DSS & DFS & DSS \\
\hline \multicolumn{2}{|l|}{ Age } & 0.001 & 0.01 & 0.027 & NS \\
\hline$<50$ years & $105(42.3)$ & & & & \\
\hline$\geq 50$ years & $143(57.7)$ & & & & \\
\hline \multicolumn{2}{|l|}{ BMI } & NS & NS & - & - \\
\hline$<25$ & $138(55.6)$ & & & & \\
\hline$\geq 25,<30$ & $82(33.1)$ & & & & \\
\hline$\geq 30$ & $28(11.3)$ & & & & \\
\hline & $<0.001$ & $<0.001$ & 0.015 & NS \\
\hline \multicolumn{2}{|c|}{ Endometrioid } & & & & \\
\hline and mixed & $225(90.7)$ & & & & \\
\hline Other type & $23(9.3)$ & & & & \\
\hline \multicolumn{2}{|l|}{ Grade } & $<0.001$ & $<0.001$ & NS & NS \\
\hline 1 & $172(69.4)$ & & & & \\
\hline 2 & $38(15.3)$ & & & & \\
\hline 3 & $32(12.9)$ & & & & \\
\hline Unknown & $6(2.4)$ & & & & \\
\hline \multicolumn{2}{|c|}{ Myometrial invasion } & $<0.001$ & 0.033 & NS & NS \\
\hline None & $95(38.3)$ & & & & \\
\hline$<1 / 2$ & $93(37.5)$ & & & & \\
\hline$\geq 1 / 2$ & $60(24.2)$ & & & & \\
\hline \multicolumn{2}{|l|}{ FIGO stage } & $<0.001$ & $<0.001$ & 0.009 & 0.019 \\
\hline I & $198(79.8)$ & & & & \\
\hline II & $24(9.7)$ & & & & \\
\hline III & $22(8.9)$ & & & & \\
\hline IV & $4(1.6)$ & & & & \\
\hline \multicolumn{2}{|c|}{ Pelvic LN metastasis } & $<0.001$ & $<0.001$ & NS & NS \\
\hline Negative & $178(71.8)$ & & & & \\
\hline Positive & $16(6.4)$ & & & & \\
\hline Unknown & $54(21.8)$ & & & & \\
\hline \multicolumn{2}{|l|}{ CA125 } & ND & $<0.001$ & - & - \\
\hline Normal & $165(66.5)$ & & & & \\
\hline Abnormal & $40(16.1)$ & & & & \\
\hline Unknown & $43(17.3)$ & & & & \\
\hline \multicolumn{2}{|l|}{ p53 mutation } & NS & 0.014 & - & 0.023 \\
\hline Negative & $79(31.9)$ & & & & \\
\hline Positive & $27(10.9)$ & & & & \\
\hline Unknown & $142(57.2)$ & & & & \\
\hline \multicolumn{2}{|c|}{ Estrogen receptor } & 0.009 & NS & NS & - \\
\hline Negative & $35(14.1)$ & & & & \\
\hline Positive & $100(40.3)$ & & & & \\
\hline Unknown & $113(45.6)$ & & & & \\
\hline \multicolumn{2}{|c|}{ Progesterone receptor } & 0.001 & 0.001 & NS & NS \\
\hline Negative & $31(12.5)$ & & & & \\
\hline Positive & $102(41.1)$ & & & & \\
\hline Unknown & $115(46.4)$ & & & & \\
\hline
\end{tabular}

Figures in parentheses are percentages. $\mathrm{LN}=$ Lymph node; $\mathrm{NS}=\mathrm{p}>0.05 ; \mathrm{ND}=$ not determined.

Gynecol Obstet Invest 2012;74:313-319 

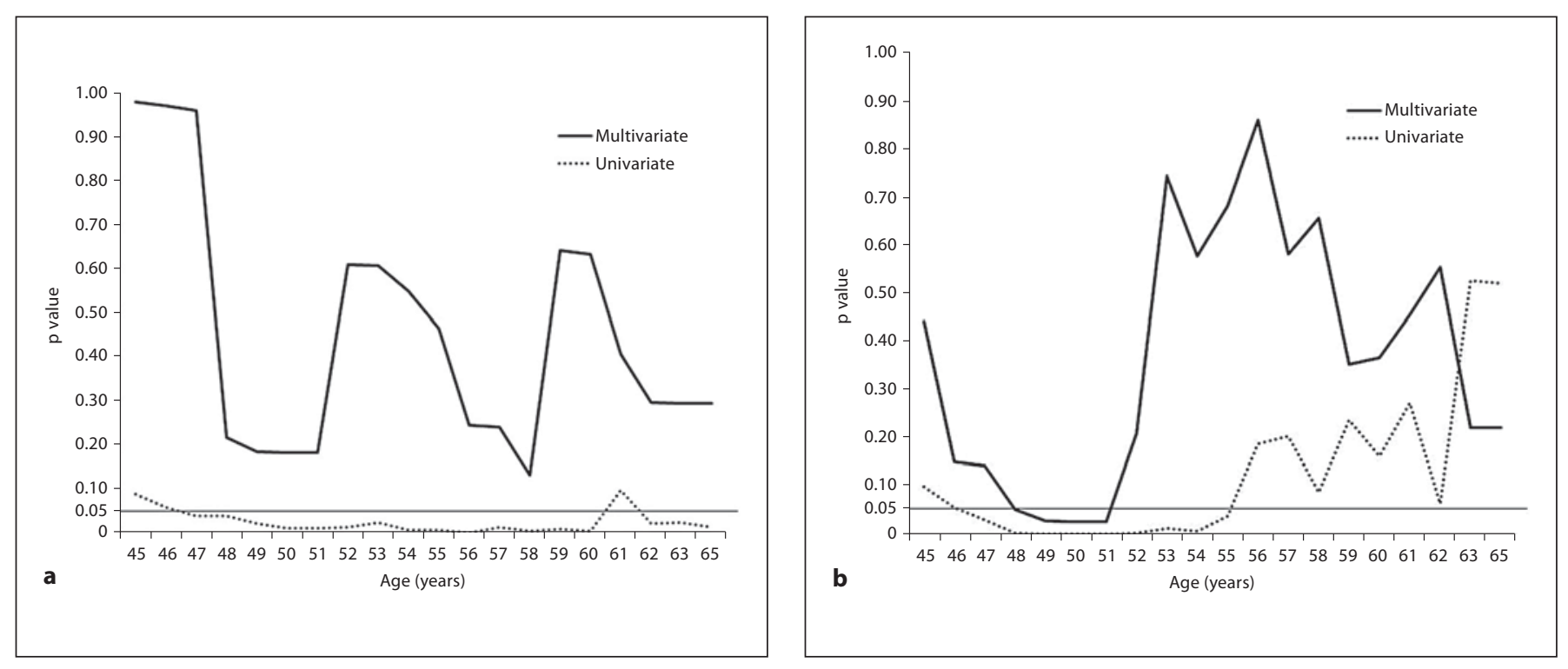

Fig. 1. p values for univariate and multivariate analyses of DSS (a), and DFS (b) in patients stratified by age.

Table 3. Histopathological data

\begin{tabular}{lc}
\hline Diagnosis & Patients, $\mathrm{n}(\%)$ \\
\hline Endometrioid adenocarcinoma & $213(85.9)$ \\
Other types & $23(9.3)$ \\
$\quad$ Papillary, serous & 11 \\
Mucinous & 4 \\
Undifferentiated & 2 \\
Clear cell & 1 \\
Adenosquamous & 1 \\
Serous and clear & 2 \\
Small round cell tumor & 1 \\
Squamous cell & 1 \\
Mixed carcinoma & $12(4.8)$ \\
Mucinous & 7 \\
Serous & 2 \\
Clear cell & 2 \\
Undifferentiated & 1 \\
\hline
\end{tabular}

for stage, histology, tumor grade, myometrial invasion, lymph node metastasis, ER status and PR status (fig. 1b). This finding suggested that the age of 50 years could be the threshold to predict clinical survival in Korean patients with endometrial cancer.

The mean follow-up interval was 56 months (range 1-151) and complete follow-up was available in 241 patients (97.2\%). Sixteen (6.5\%) patients died, 26 patients
(10.5\%) experienced recurrence and 2 patients $(0.8 \%)$ showed disease progression without a disease-free interval (persistent disease). Univariate survival analysis showed that age, histopathology type, tumor grade, myometrial invasion, FIGO stage, pelvic lymph node metastasis, ER status and PR expression are associated with DFS. Moreover, age, histopathology type, tumor grade, myometrial invasion, FIGO stage, pelvic lymph node metastasis, serum CA125, p53 mutation and PR status were associated with DSS (table 2). Cox multivariate analysis for an association between prognostic factors (age, stage, histopathology, tumor grade, myometrial invasion, lymph node metastasis, and ER and PR status) and DFS showed that older age, advanced tumor stage and other histopathology type are associated with a worse prognosis $(\mathrm{p}=0.027, \mathrm{p}=0.009$ and $\mathrm{p}=0.015$, respectively). Multivariate analysis adjusted for age, tumor stage, histopathology, tumor grade, myometrial invasion, lymph node metastasis, p53 mutation and PR status showed that an advanced FIGO stage and the presence of a p53 mutation are strongly associated with a poor DSS rate $(\mathrm{p}=0.019$ and $\mathrm{p}=0.023$, respectively).

The estimated overall cumulative 5-year and 10-year survival rates for all patients were 92.1 and $86 \%$, respectively. A significant correlation was observed between DFS or DSS and disease stage ( $p<0.001$; fig. $2 a)$. When the patients were stratified by the presence of p53 mutation, the 5-year DSS was significantly shorter in the group 

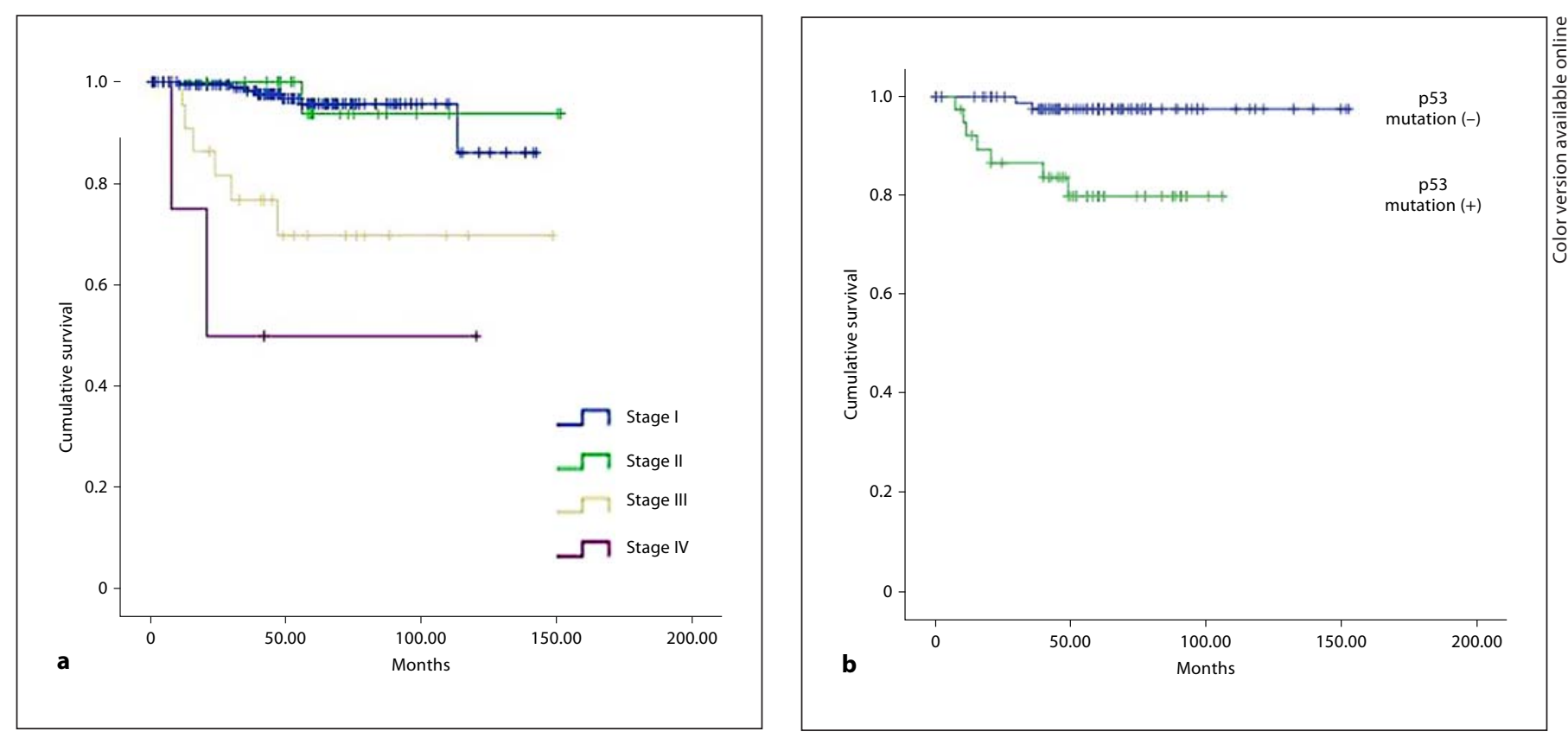

Fig. 2. Kaplan-Meier actuarial survival curves for patients with endometrial carcinoma. Significant differences were observed in the overall cumulative DSS according to stage (a; log-rank test, $\mathrm{p}<0.001)$. Women with tumors carrying a p53 mutation had a lower cumulative survival rate than women with no mutation (b; log-rank test, $\mathrm{p}=0.014)$.

with the mutation $(84.4 \%)$ than in the group without it (97.1\%); this difference is statistically significant (logrank, $\mathrm{p}=0.014$; fig. $2 \mathrm{~b}$ ).

\section{Discussion}

In this study, two distinctive features of Korean patients with endometrial cancer were identified compared with Western women. One was age at diagnosis, which has long been recognized as a clinical predictor of survival. Based on previous studies, endometrial cancer is more likely to develop in elderly women with an average age in the early 60 s $[15,16]$, and advanced age is associated with a poorer prognosis. In the present study, the median age of the patients was 51 years, suggesting that endometrial cancer is developing at a younger age in the Korean population than in Western women. Since the PORTEC study, which showed that the risk of local/regional relapse and death is significantly higher for patients aged 60 years and over compared with those below 60 [17], 60 years has been used as an arbitrary age to predict prognosis and to indicate the need for adjuvant radiotherapy. However, our multivariate analysis failed to show a statistically significant difference between patients aged 60 years and over and those below this age. The level of significance was highest in the multivariate analysis when the patients were stratified according to ages 49,50 and 51 years (fig. 1). Thus, the age of 50 years might be a more meaningful threshold to predict disease survival for patients with endometrial cancer in the Korean population. Further studies are necessary to confirm this finding.

The other distinctive feature of this study population was the BMI. Epidemiological studies have reported that a BMI of 25 or greater is an important risk factor for endometrial cancer $[18,19]$. Obesity is a common factor associated with excess estrogen exposure, which increases the mitotic activity of endometrial cells and promotes cellular replication, leading to hyperplasia and eventually to carcinoma. In this Korean population, patients with endometrial cancer and a BMI of 25 or greater accounted for $44.4 \%$ of the cases, which is lower than the range of $66.9-83.9 \%$ reported previously [20]. More than half of our patients (55.6\%) were of normal weight or underweight, and no relationship was found between BMI and histopathology (data not shown). Results from a multiethnic cohort study, showing a positive dose-response 
relationship between BMI gain and the risk of endometrial cancer might partially explain our finding [21]. In particular, Asian women showed an increase in risk after a BMI gain of $\geq 5 \%$ whereas Africans and Caucasians showed an increase in risk with a much larger gain $(\geq 35 \%)$. Since a smaller BMI gain increased the risk of endometrial cancer in Asian women, an increase in adiposity may contribute to the development of endometrial cancer in normal-weight or underweight women. Another possible explanation might be the effects of nonestrogenic factors, such as race differences in epigenetic factors [22], polymorphism in hormonal receptors [23], or alternative oncological mediators, including aneuploidy and mutations in PTEN, K-ras and p53 [24].

According to Creasman et al. [25], the 5-year survival rate is $91 \%$ for patients with stage Ia cancers, $91 \%$ for stage $\mathrm{Ib}, 85 \%$ for stage Ic, $83 \%$ for stage IIa, $66 \%$ for stage IIb, $50 \%$ for stage IIIa, $50 \%$ for stage IIIb, $57 \%$ for stage IIIc and $25 \%$ for stage IV. In the present single-institution study, the patients' survival characteristics were better than these values for all tumor stages. This finding is partially explained by the fact that the patients were younger than those included in previous studies. Women aged less than 50 years had a significantly better survival rate than those aged 50 years or older, and $42.3 \%$ of patients in this study were younger than 50 .

The therapeutic effects of para-aortic lymphadenectomy in patients with endometrial cancer remain unproven. Studies that have compared the prognosis of a para-aortic lymphadenectomy group with a non-paraaortic lymphadenectomy group [26-28] have reported conflicting results. Additionally, two prospective randomized studies failed to show any therapeutic benefit of this procedure $[29,30]$. In the present study, although only 8 of the 248 patients received para-aortic lymphad- enectomy, and these nodes were negative on pathology, no abatement was observed in the survival rate for these patients. Therefore, we did not obtain any scientific evidence supporting the role of para-aortic lymphadenectomy.

Many clinical and histopathological variables, such as age, BMI, histopathology, tumor grade, depth of myometrial invasion, FIGO stage, lymph node involvement, abnormal CA125 serum level, presence of a p53 mutation, and ER and PR status affect the clinical outcome of patients treated for endometrial cancer. With the exception of BMI, the correlation of these factors with the DFS and DSS prognosis was confirmed by univariate analysis in the present study. Multivariate analysis showed that age, FIGO stage and histopathology were independent prognostic factors associated with DFS whereas FIGO stage and the presence of a p53 mutation were the only variables that correlated significantly with DSS.

In conclusion, this study revealed the independent prognostic factors associated with survival in Korean patients with endometrial cancer. Our patients were younger and had a lower BMI compared with those in previous studies on Western patients with endometrial cancer. Our data indicated that 50 years might be a more appropriate threshold age to predict patient survival in Korean women. However, these results must be confirmed by studies including a larger number of patients.

\section{Acknowledgements}

This study was supported by a grant from the Korea Healthcare Technology R\&D Project, Ministry for Health, Welfare \& Family Affairs, Republic of Korea (A085138) and by a Korea Science and Engineering Foundation (KOSEF) grant funded by the Korea government (MEST) (2010-0005333).

\section{References}

1 Parkin DM, Bray F, Ferlay J, Pisani P: Global cancer statistics, 2002. CA Cancer J Clin 2005;55:74-108.

-2 Bakkum-Gamez JN, Gonzalez-Bosquet J, Laack NN, Mariani A, Dowdy SC: Current issues in the management of endometrial cancer. Mayo Clin Proc 2008;83:97-112.

- 3 Ushijima K: Current status of gynecologic cancer in japan. J Gynecol Oncol 2009;20: 67-71.

4 Lee HP: Recent clinical review: annual report of gynecologic cancer registry program in Korea: 1991-2004. Korean J Obstet Gynecol 2008;51:1411-1420.
5 Creasman WT, Morrow CP, Bundy BN, Homesley HD, Graham JE, Heller PB: Surgical pathologic spread patterns of endometrial cancer. A Gynecologic Oncology Group study. Cancer 1987;60:2035-2041.

6 Gal D, Recio FO, Zamurovic D: The new International Federation of Gynecology and Obstetrics surgical staging and survival rates in early endometrial carcinoma. Cancer 1992;69:200-202.
Kosary CL: FIGO stage, histology, histologic grade, age and race as prognostic factors in determining survival for cancers of the female gynecological system: an analysis of 1973-87 SEER cases of cancers of the endometrium, cervix, ovary, vulva, and vagina. Semin Surg Oncol 1994;10:31-46.

8 Alektiar KM, McKee A, Lin O, Venkatraman E, Zelefsky MJ, McKee B, Hoskins WJ, Barakat RR: Is there a difference in outcome between stage I-II endometrial cancer of papillary serous/clear cell and endometrioid FIGO grade 3 cancer? Int J Radiat Oncol Biol, Phys 2002;54:79-85. 
-9 Creasman WT, Kohler MF, Odicino F, Maisonneuve P, Boyle P: Prognosis of papillary serous, clear cell, and grade 3 stage I carcinoma of the endometrium. Gynecol Oncol 2004;95:593-596.

10 Lee EJ, Kim TJ, Kim DS, Choi CH, Lee JW, Lee JH, Bae DS, Kim BG: p53 alteration independently predicts poor outcomes in patients with endometrial cancer: a clinicopathologic study of 131 cases and literature review. Gynecol Oncol 2010;116:533-538.

11 Creasman WT: New gynecologic cancer 18 staging. Obstet Gynecol 1990;75:287-288.

12 Scully RE, Poulson H: International Classification and Histologic Typing of Female Genital Tract Tumors. New York, Springer, 1994.

13 Kurman RJ, Zaino RJ, Norris HJ: Endometrial carcinoma; Blaustein's Pathology of the Female Genital Tract. New York, Springer, 1994, pp 439-486.

-14 Sherman ME, Bitterman P, Rosenshein NB, Delgado G, Kurman RJ: Uterine serous carcinoma. A morphologically diverse neoplasm with unifying clinicopathologic features. Am J Surg Pathol 1992;16:600-610.

15 Farley JH, Nycum LR, Birrer MJ, Park RC, Taylor RR: Age-specific survival of women with endometrioid adenocarcinoma of the uterus. GynecolOncol 2000;79:86-89.

$\checkmark 16$ Madison T, Schottenfeld D, James SA, Schwartz AG, Gruber SB: Endometrial cancer: socioeconomic status and racial/ethnic differences in stage at diagnosis, treatment, and survival. Am JPublic Health 2004;94: 2104-2111.
17 Creutzberg CL, van Putten WL, Koper PC, Lybeert ML, Jobsen JJ, Warlam-Rodenhuis CC, De Winter KA, Lutgens LC, van den Bergh AC, van de Steen-Banasik E, Beerman $H$, van Lent M: Surgery and postoperative radiotherapy versus surgery alone for patients with stage-1 endometrial carcinoma: multicentre randomised trial. PORTEC Study Group. Post Operative Radiation Therapy in Endometrial Carcinoma. Lancet 2000;355: 1404-1411.

18 Amant F, Moerman P, Neven P, Timmerman D, Van Limbergen E, Vergote I: Endometria cancer. Lancet 2005;366:491-505.

19 Calle EE, Kaaks R: Overweight, obesity and cancer: epidemiological evidence and proposed mechanisms. NatRev 2004;4:579-591.

20 Temkin SM, Pezzullo JC, Hellmann M, Lee YC, Abulafia O: Is body mass index an independent risk factor of survival among patients with endometrial cancer? Am J Clin Oncol 2007;30:8-14.

21 Park SL, Goodman MT, Zhang ZF, Kolonel LN, Henderson BE, Setiawan VW: Body size, adult BMI gain and endometrial cancer risk: the multiethnic cohort. Int J Cancer 2010; 126:490-499.

22 Lee JS, Lo PK, Fackler MJ, Argani P, Zhang Z, Garrett-Meyer E, Sukumar S: A comparative study of Korean with Caucasian breast cancer reveals frequency of methylation in multiple genes correlates with breast cancer in young, ER, PR-negative breast cancer in Korean women. Cancer Biol Ther 2007;6: 1114-1120.

23 Fujimoto J, Hirose R, Ichigo S, Sakaguchi H, Tamaya T: DNA polymorphism in B-domain of the estrogen receptor-alpha among Japanese women. Steroids 1998;63:146-148.

24 Hecht JL, Mutter GL: Molecular and pathologic aspects of endometrial carcinogenesis. J Clin Oncol 2006;24:4783-4791.
25 Creasman WT, Odicino F, Maisonneuve P, Quinn MA, Beller U, Benedet JL, Heintz AP, Ngan HY, Pecorelli S: Carcinoma of the corpus uteri. FIGO 6th Annual Report on the Results of Treatment in Gynecological Cancer. Int J Gynaecol Obstet 2006;95(suppl 1):S105-S143.

26 Mariani A, Webb MJ, Galli L, Podratz KC: Potential therapeutic role of para-aortic lymphadenectomy in node-positive endometrial cancer. Gynecol Oncol 2000;76:348356.

27 Cragun JM, Havrilesky LJ, Calingaert B, Synan I, Secord AA, Soper JT, Clarke-Pearson DL, Berchuck A: Retrospective analysis of selective lymphadenectomy in apparent early-stage endometrial cancer. J Clin Oncol 2005;23:3668-3675.

28 Todo Y, Kato H, Kaneuchi M, Watari H, Takeda M, Sakuragi N: Survival effect of para-aortic lymphadenectomy in endometrial cancer (SEPAL study): a retrospective cohort analysis. Lancet 2010;375:1165-1172.

29 Kitchener H, Swart AM, Qian Q, Amos C, Parmar MK: Efficacy of systematic pelvic lymphadenectomy in endometrial cancer (MRC ASTEC trial): a randomised study. Lancet 2009;373:125-136.

30 Benedetti Panici P, Basile S, Maneschi F, Alberto Lissoni A, Signorelli M, Scambia G, Angioli R, Tateo S, Mangili G, Katsaros D, Garozzo G, Campagnutta E, Donadello N, Greggi S, Melpignano M, Raspagliesi F, Ragni N, Cormio G, Grassi R, Franchi M, Giannarelli D, Fossati R, Torri V, Amoroso M, Croce C, Mangioni C: Systematic pelvic lymphadenectomy vs. no lymphadenectomy in early-stage endometrial carcinoma: randomized clinical trial. J Natl Cancer Inst 2008;100:1707-1716 